\title{
PERPETUUS MOTUUS E A ENTROPIA INDEPENDENTE NO MESMO CICLO
}

\section{ARTIGO ORIGINAL}

DIAS, Francisco Valdevan Alves ${ }^{1}$

DIAS, Francisco Valdevan Alves. Perpetuus Motuus e a entropia independente no mesmo ciclo. Revista Científica Multidisciplinar Núcleo do Conhecimento. Ano 06, Ed. 06, Vol. 08, pp. 82-99. Junho de 2021. ISSN: 2448-0959, Link de acesso: https://www.nucleodoconhecimento.com.br/engenharia-eletrica/mesmo-ciclo, DOI: 10.32749/nucleodoconhecimento.com.br/engenharia-eletrica/mesmo-ciclo

\section{RESUMO}

O presente trabalho objetiva mostrar o desenvolvimento de um sistema de movimento contínuo para a geração de energia elétrica, que recebendo uma força inicial, produz energia para seu próprio trabalho indefinidamente: Um gerador de energia Infinita. De acordo com a segunda lei da termodinâmica, um Moto-Perpétuo mecânico, máquina de movimento perpétuo, é impossível acontecer na natureza. A nova proposta é o Perpetuus Motuus; surgiu das observações iniciais dos equipamentos analisados isoladamente e originaram a fundamentação necessária ao experimento, subsidiado por alguns referenciais teóricos. Apresentaremos o desenvolvimento do Perpetuus Motuus a partir do conceito denominado entropia independente no mesmo ciclo, que nos fez compreender que a energia infinita é possível sim de ser gerada, não criada do nada, mas observamos que a mesma pode ser gerada a partir de uma força existente para em seguida tornar-se independente, com essa força aplicada no sistema, os equipamentos tecnológicos trabalharão de forma harmônica fazendo com que seu trabalho final seja maior que seu trabalho inicial, ganhando força, aceleração e potência. Diante do exposto pode-se afirmar que gerar energia infinitamente dentro

\footnotetext{
${ }^{1}$ Servidor Público Municipal, Ensino Médio.
}

$\mathrm{RC}: 88483$

Disponível em: https://www.nucleodoconhecimento.com.br/engenharia-eletrica/mesmo-ciclo 
do conceito da entropia independente no mesmo ciclo, onde as entropias não interferem nos resultados umas das outras diretamente é possível conforme experimentos realizados e com base nas especificações técnicas de cada equipamento, o sistema ao receber uma força inicial $X$ a produção final foi $10 X$.

Palavras-chave: Entropia, Energia Infinita, Perpetuus Motuus, Entropia independente, Perpetuum Móbile.

\section{INTRODUÇÃO}

A entropia é uma grandeza termodinâmica que mede o grau de desordem ou aleatoriedade de um sistema físico, à qual é associada à irreversibilidade dos estados de um sistema físico. Um milho de pipoca ao ser aquecido ele se transforma em pipoca, esse processo é espontâneo já que se espera esse resultado, porém não se espera que o processo inverso aconteça naturalmente, isto é, a pipoca transformandose em milho novamente. Se isso fosse possível a entropia do sistema diminuiria e o processo seria não espontâneo (WALKER, 2016).

No conceito da termodinâmica um sistema termicamente isolado, a medida da entropia deve sempre aumentar com o tempo, até atingir seu valor máximo. A entropia é medida em kelvin (K), e sua fórmula é dada pela razão entre a quantidade de calor transferida durante um processo isotérmico pela temperatura em que esse processo ocorreu. Fórmula: $\Delta \mathrm{S}=\Delta \mathrm{S}=S_{f}-S_{i}-\Delta \mathrm{S}=\frac{\Delta Q}{T}-\Delta \mathrm{S}$ - variação de entropia $-\Delta \mathrm{Q}-$ quantidade de calor $-\mathrm{T}-$ temperatura ${ }^{-S_{f}-}$ Entropia Final ${ }^{-S_{i}-}$ Entropia Inicial durante um processo isotérmico $(\Delta Q<0)$, quando um sistema perde calor, sua entropia diminui. Quando um sistema recebe calor $(\Delta Q>0)$, sua entropia aumenta. Por fim, quando um sistema não realiza trocas de calor $(\Delta Q=0)$, sua entropia permanece constante, (YOUNG e FREEDMAN, 2008).

$\mathrm{RC}: 88483$

Disponível em: https://www.nucleodoconhecimento.com.br/engenharia-eletrica/mesmo-ciclo 
Para o sistema proposto será levado em consideração apenas a entropia final resultante no sistema, já que do início até o final do ciclo, todos os processos termodinâmicos já foram compensados pelos componentes tecnológicos envolvidos. Um projeto mais parecido com a lei dos gases ideais, ciclo de Carnot. (WALKER, 2016).

De acordo com a termodinâmica, se pegarmos uma seringa, taparmos o bico e apertarmos o cabo, percebemos que só é possível fechar até um certo ponto, pois a pressão vai fazer uma força contrária que tende ao equilíbrio. Essa força contrária acontece por conta do aumento da pressão e diminuição da entropia dentro da seringa. Com base nessa lei um moto-contínuo (mecânico) conhecido também pelo seu termo em latim de perpetuum mobile é impossível acontecer na natureza, pois viola pelo menos a primeira e segunda lei da termodinâmica (WALKER, 2016).

O sistema aqui proposto é mais parecido com a máquina de Carnot, (1820), o diferencial é a capacidade de se realimentar, pois os componentes tecnológicos envolvidos no sistema conseguem realizar os ajustes térmicos, pressão e velocidade. Sua capacidade de funcionamento pode desenvolver um trabalhando em harmonia de forma precisa, permitindo fazer com que seu trabalho final seja maior que seu trabalho inicial. Esse sistema não é um moto-contínuo (Perpetuum Móbile) e sim um Perpetuus Motuus (em português movimento Perpétuo). Perpetuus Motuus no latim com 'us' no final significa (Nós) fazendo uma conotação da necessidade de pessoas trabalhando em conjunto, aplicando uma força inicial, inteligência para garantir seu funcionamento.

\section{DESENVOLVIMENTO}

Para explicar o funcionamento do sistema proposto é muito importante entender a entropia independente no mesmo ciclo. O sistema consiste em um gerador de energia por pressão de ar comprimido, em que os principais equipamentos utilizados são: um compressor de Ar (figura 1), uma chave pneumática de impacto (figura 2) e um

RC: 88483

Disponível em: https://www.nucleodoconhecimento.com.br/engenharia-eletrica/mesmo-ciclo 
alternador de energia (figura 3), ligados inicialmente em um ciclo aberto para em um determinado momento fechar o ciclo.

Figura 1: Compressor de Ar.

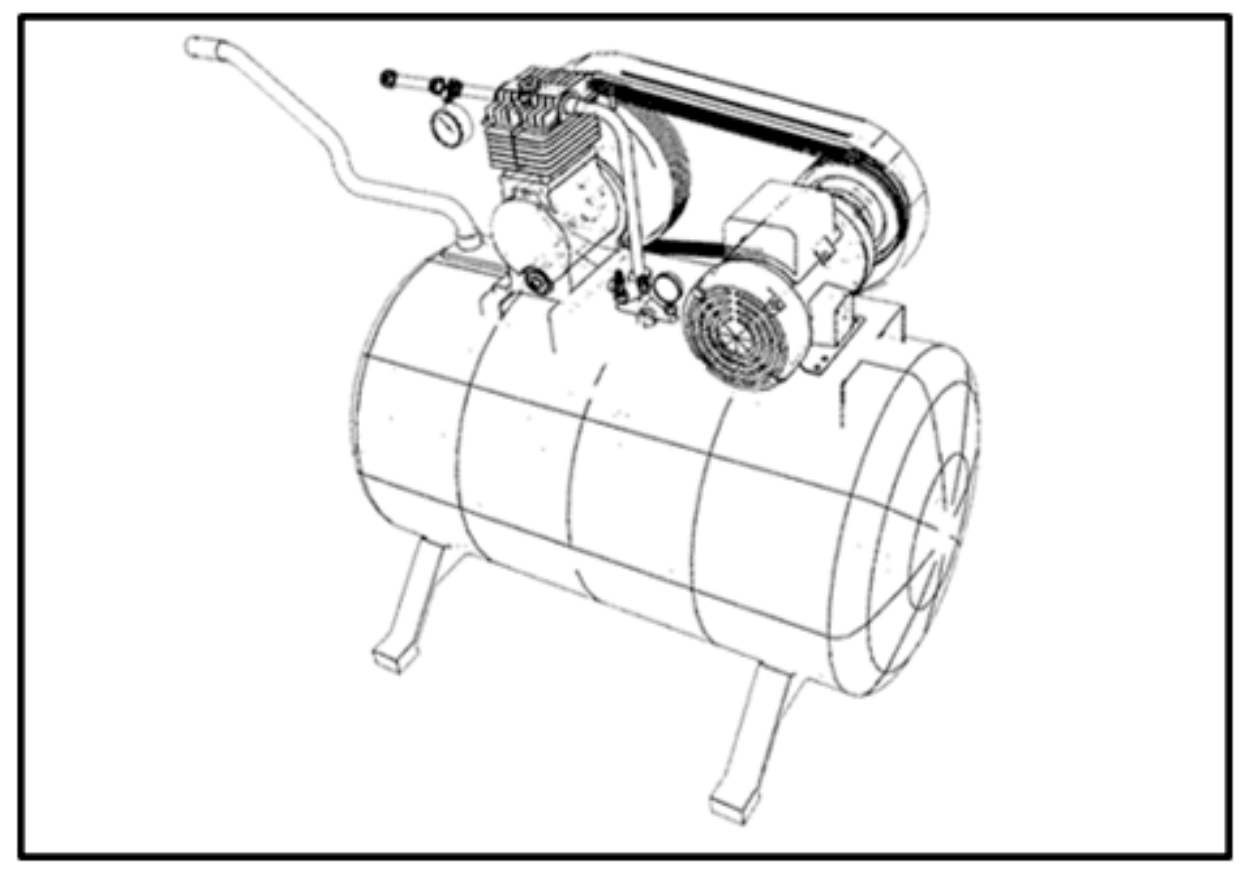

Fonte: elaboração própria, 2021.

$\mathrm{RC}: 88483$

Disponível em: https://www.nucleodoconhecimento.com.br/engenharia-eletrica/mesmo-ciclo 


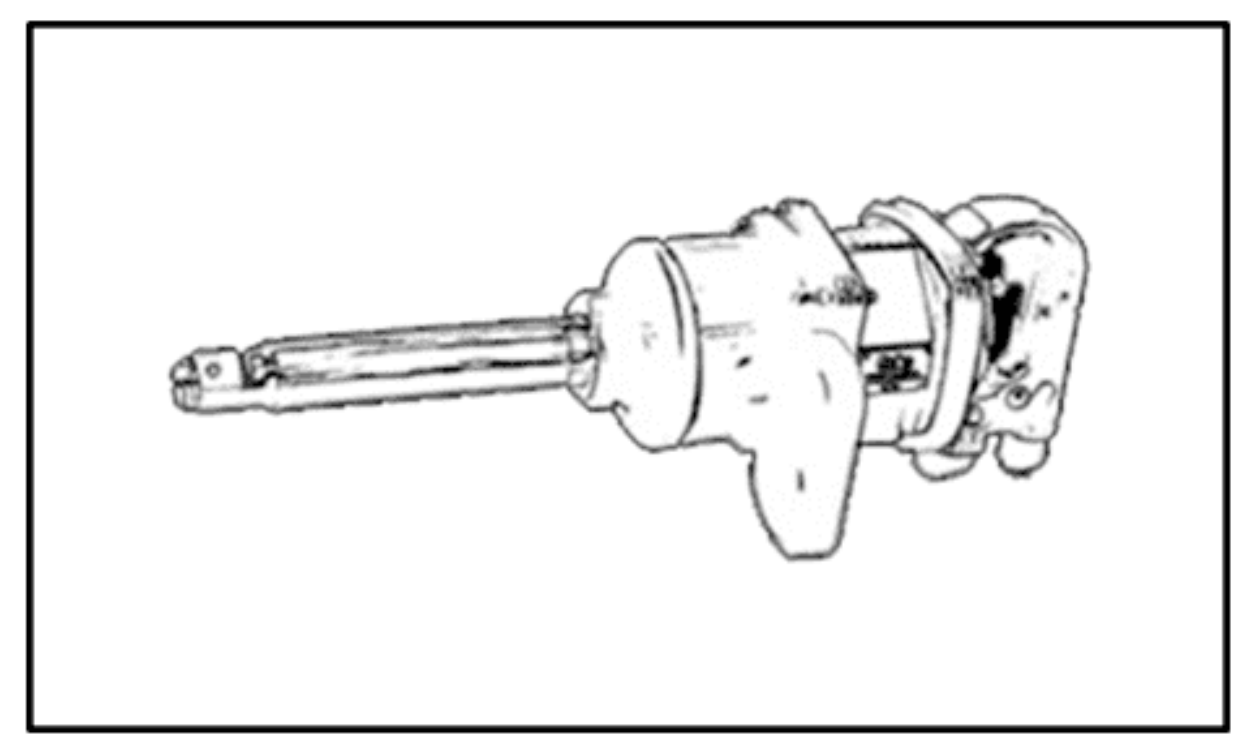

Fonte: elaboração própria, 2021.

Figura 3: Alternador de energia.

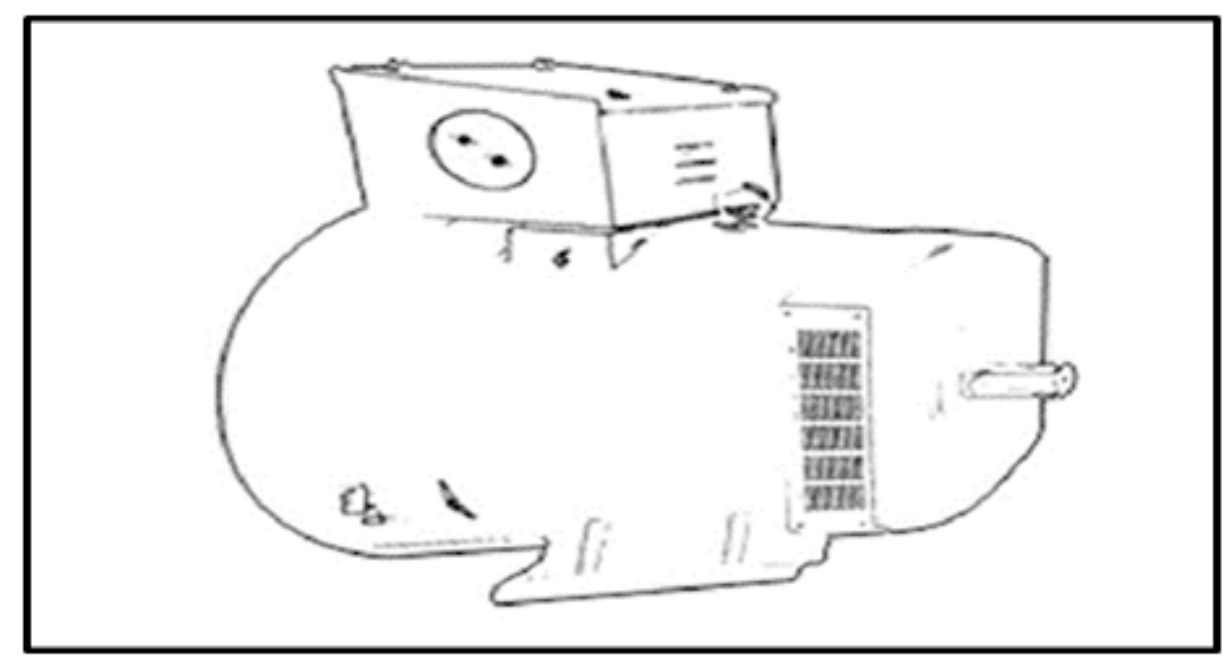

Fonte: elaboração própria, 2021.

Para mostrar a entropia independente no mesmo ciclo, será usado o cabeçote do compressor de ar; o cilindro do compressor que armazena o ar; o tanque da chave pneumática que armazena, transforma em trabalho e energia cinética. Os pistões

RC: 88483

Disponível em: https://www.nucleodoconhecimento.com.br/engenharia-eletrica/mesmo-ciclo 
contidos nos compressores, trabalham de forma semelhante aos pistões de combustão interna. (YOUNG e FREEDMAN, 2008).

Figura 4: Representa a parte interna do cabeçote.

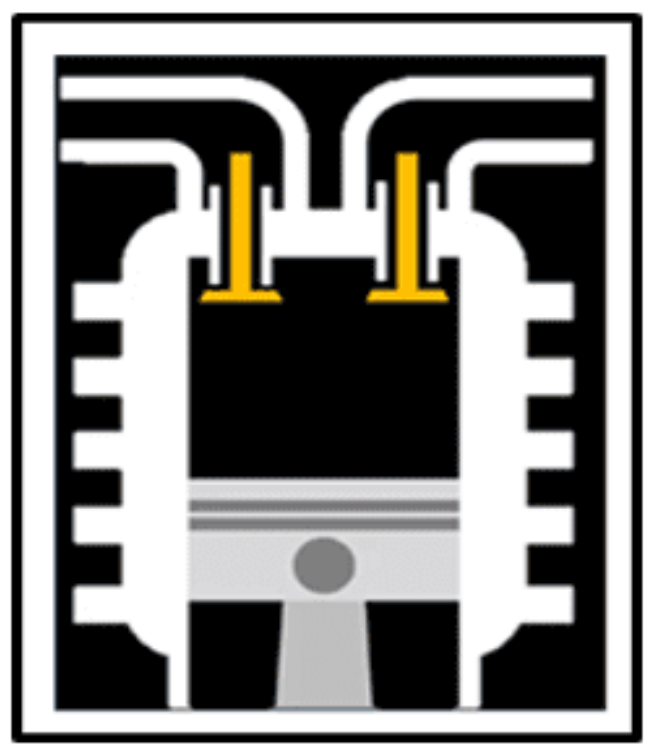

Fonte: elaboração própria, 2021.

As imagens na figura 5, representam os estágios em que a câmara de compressão se encontra durante seu trabalho; S0, motor desligado; $\mathrm{Si}$, entropia inicial onde a válvula de admissão está aberta e a de expansão fechada; S2, as duas válvulas fechadas e o pistão comprimido o ar; S3, a válvula de admissão fechada o pistão está comprimindo e a válvula de expansão abre no momento certo em um rápido movimento, (YOUNG e FREEDMAN, 2008).

$\mathrm{RC}: 88483$

Disponível em: https://www.nucleodoconhecimento.com.br/engenharia-eletrica/mesmo-ciclo 
Figura 5: Estados da câmara de compressão.

S0

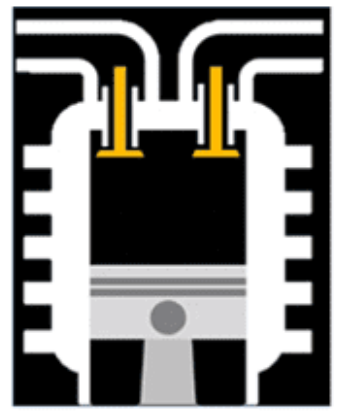

$\mathrm{S} 1$

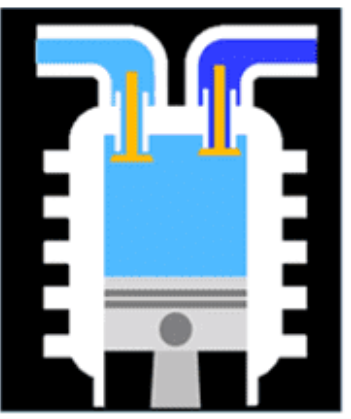

S2

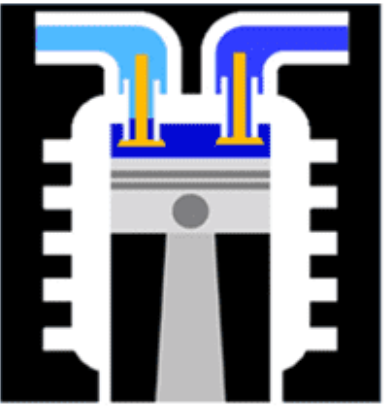

S3

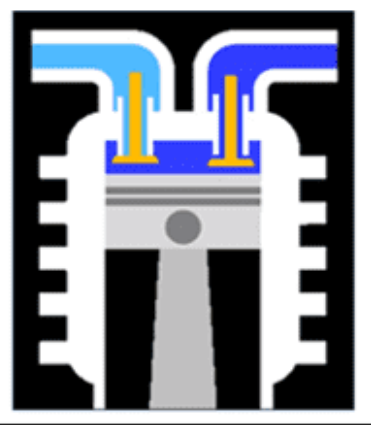

Fonte: elaboração própria, 2021.

Para o funcionamento do compressor (figura 1), será usado um compressor de ar comprimido que trabalha com um motor elétrico de $5 \mathrm{CV}$ ligado a uma força externa de energia (figura 6).

$\mathrm{RC}: 88483$

Disponível em: https://www.nucleodoconhecimento.com.br/engenharia-eletrica/mesmo-ciclo 
Figura 6: Compressor ligado a uma força externa.

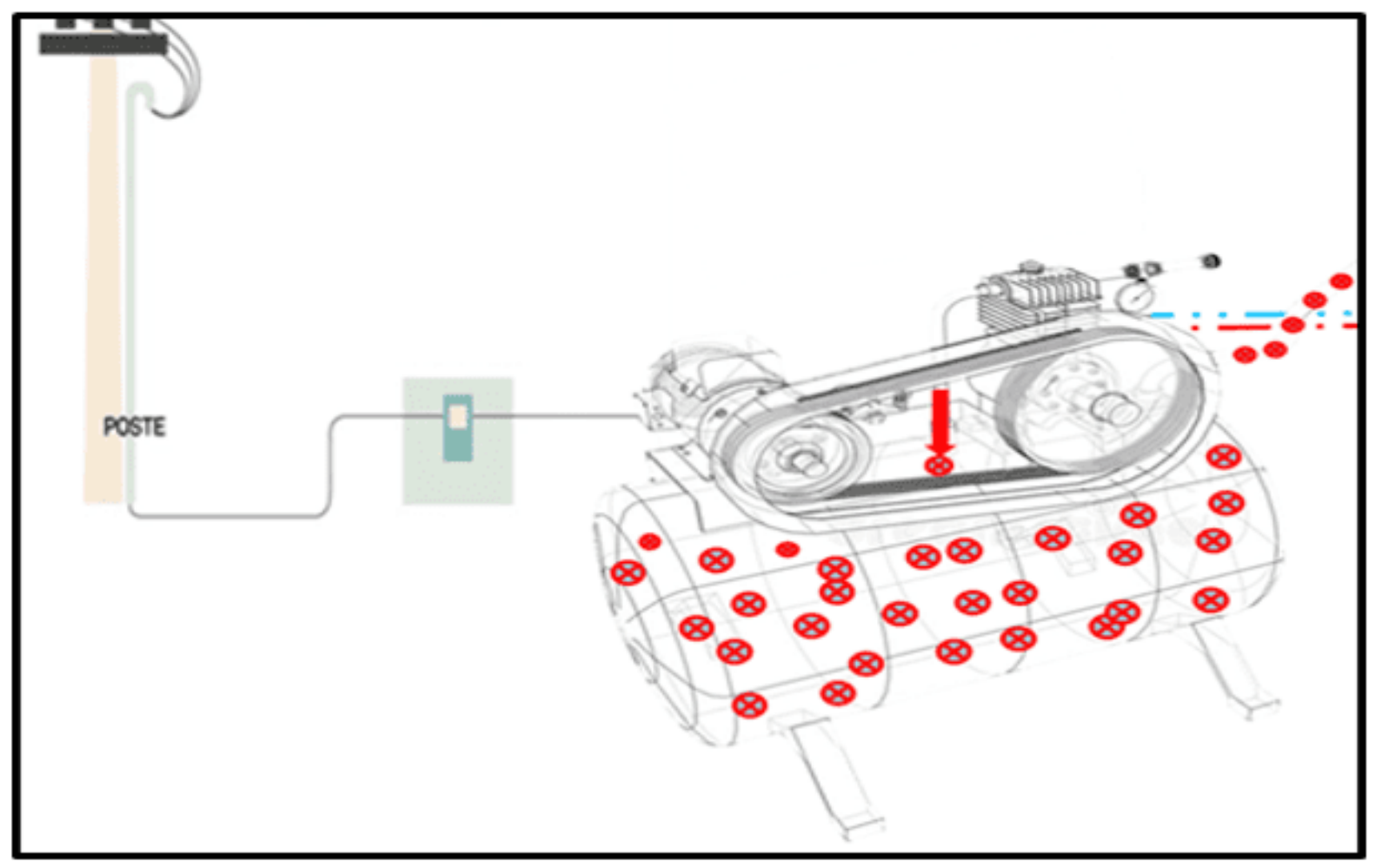

Fonte: elaboração própria, 2021.

O trabalho é iniciado com as válvulas fechadas e o pistão fechado, ao ligar o motor o pistão desce fazendo um vácuo, a válvula de admissão abre e o ar é sugado para a câmara, na qual encontra uma determinada entropia; em seguida o pistão começa subir, a válvula de admissão fecha e o ar é comprimido fortemente, aumentando a pressão e diminuindo a entropia, no tempo exato durante a compressão a válvula de expansão se abre e o ar é empurrado para o sistema. Tudo isso acontece de forma muito rápida ocasionando muitos fenômenos como aquecimento, resfriamento, aumento de pressão, queda de pressão, aceleração e condensação. Porém para que isso aconteça e o ar chegue até o cilindro do compressor é realizado todo um trabalho pelos equipamentos tecnológicos contidos no compressor. Um compressor é uma ferramenta muito conhecida no mercado, portanto não entraremos em detalhes de como essas compensações são feitas, continuando a partir do gás pronto, em condições ideais para ser usado. $\mathrm{O}$ ar entra no cilindro do compressor já tratado,

RC: 88483

Disponível em: https://www.nucleodoconhecimento.com.br/engenharia-eletrica/mesmo-ciclo 
encontra uma entropia diferente em relação a anterior, na qual vai diminuindo de acordo com a quantidade de ar que entra, as válvulas impedem o ar de voltar e o cilindro apenas recebe carga, quando o cilindro do compressor chega a 12 Newtons, 175 psi e 250 litros, alcança sua capacidade máxima e desliga automaticamente o motor que o alimenta, esse processo leva em média 8 minutos. Nesse momento o compressor está pronto para fornecer o ar ideal para a chave pneumática. A chave pneumáticas ao receber a pressão de ar começa acumular, esperando a força necessária para seu funcionamento, a chave tem um mecanismo de bomba movida a gás que força continuamente $o$ ar para dentro de um tanque de aço, até que 0 ar se torne pressurizado, alcance alta pressão e baixa entropia; após ser acionado o gatilho que pode ser manual ou automático, o ar faz uma força, girando os mecanismos em alta velocidade e capacidade elevada de torque; a chave pode atingir $3.900 \mathrm{rpm}$ e $2.400 \mathrm{~N} . \mathrm{m}, 244.8 \mathrm{Kgfm}$ de torque. Com o gerador acoplado ao rotor da chave pneumática, que pode ser através de polias, correias, engrenagens ou até mesmo direto ao eixo, o trabalho realizado pela chave pneumática faz girar o eixo do gerador de energia. A chave pneumática estará com muito torque e baixa rotação; como a força da chave é muito alta, o alternador começará gerar energia; na medida em que a rotação aumenta o alternador começa fazer uma força contrária; a chave para compensar essa resistência joga seus martelos de impacto - componentes que fazem parte do equipamento interno - o compressor nesse momento estará trabalhando apenas com o ar do seu tanque, desligado da força elétrica e fornecendo o ar para a chave pneumática; após um dado período, que em média leva um minuto de acordo com experimentos realizados, o gerador alcança sua rotação máxima, 1800 rpm, enquanto a chave pneumática estará fazendo uma força menor em relação à força inicial, devido a velocidade do rotor e caixas multiplicadoras. A chave pneumática passa a trabalhar abaixo da sua capacidade para economizar o máximo possível de ar, mas com rpm suficiente para o alternador que estará produzindo até 12.900 Watts de potência e corrente de 58,4 / 33,9 A. Com a perda de pressão o motor será acionado automaticamente quando o cilindro do compressor estiver abaixo de $90 \mathrm{psi}$, pressão usada pela chave pneumática, porém para o religamento do motor do 
compressor, a energia virá do próprio alternador, fechando o ciclo para realizar o trabalho de forma independente, podendo assim continuar funcionando indefinidamente.

Figura 7: Ciclo do Perpetuus Mótuus.

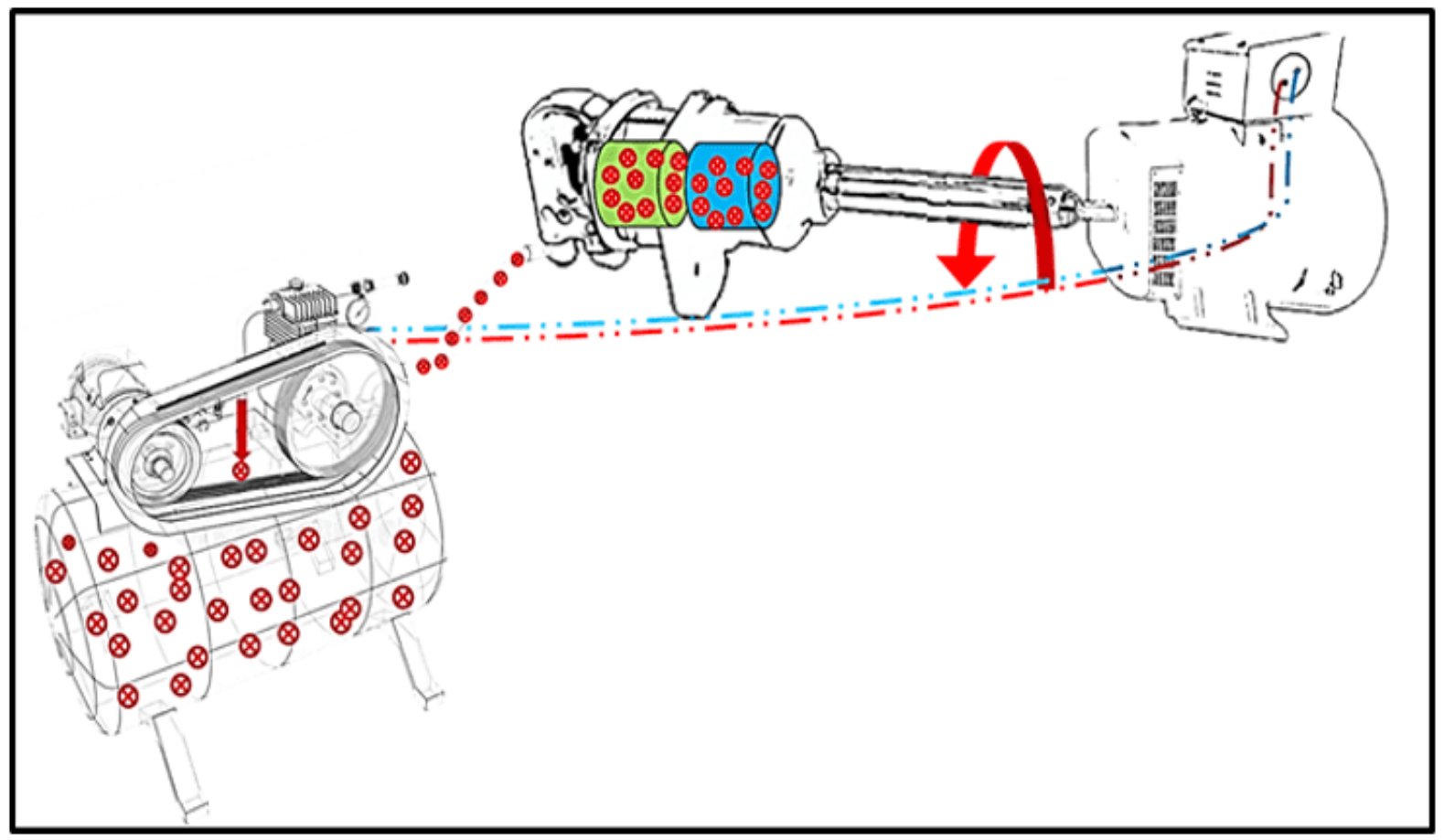

Fonte: elaboração própria, 2021.

Para relacionar a entropia com o trabalho e energia, foram realizados experimentos, vale ressaltar que os experimentos da figura 8 são exemplos didáticos para se ter um melhor entendimento da forma que as entropias trabalham dentro do sistema proposto e como a entropia independente no mesmo ciclo variam de acordo com a sequência estratégica aplicada. Na imagem 1 da figura 8, uma pessoa está com um peso erguido com os dois braços esticados, embora não pareça que esteja realizando trabalho, na realidade está sim, mas internamente pelo sistema do corpo da pessoa, onde as células estão esticando e contraindo realizando trabalho a nível microscópico. A cada tempo que passa o braço vai baixando por conta do cansaço. O sistema do corpo trabalha em harmonia para compensar as trocas de energia no processo, tornando

RC: 88483

Disponível em: https://www.nucleodoconhecimento.com.br/engenharia-eletrica/mesmo-ciclo 
deste modo perceptível a oscilação da temperatura, desestabilização dos braços e mudança na coloração da pele. No exemplo da imagem 1 , figura 8 , foi possível manter o peso erguido por 2 minutos, (WALKER, 2016).

Nas imagens 2 e 3 da figura 8, a massa e altura permaneceram as mesmas do exemplo anterior, porém ele segura o peso erguendo apenas um dos braços, enquanto o outro está abaixado; quando ele começa a baixar o braço pelo cansaço ocasionado no trabalho interno, ele ergue o outro braço e troca o peso de mãos como mostrado na imagem 3, mantendo o peso na mesma faixa de altura e baixa o braço cansado para descansar; deste modo, enquanto descansa, a entropia dentro do sistema muda fazendo os ajustes de pressão e temperatura. Esse processo é repetido até não suportar mais segurar o peso, podendo repetir o movimento da troca dos braços, quantas vezes for necessário. Neste último exemplo o resultado foi 10 vezes maior, mantendo o peso erguido por 20 minutos. Apesar de ser o mesmo sistema, peso e altura igual o sistema realizou trabalho de forma diferente, onde o trabalho do braço realizado no deslocamento de baixo para cima e de cima para baixo na troca dos braços, foi menor do que o trabalho com os dois braços erguidos, devido às compensações térmicas feitas pelo sistema, o que proporcionou um ganho muito maior ao executar o trabalho de forma estratégica e inteligente (WALKER, 2016).

Figura 8: experimento realizado.

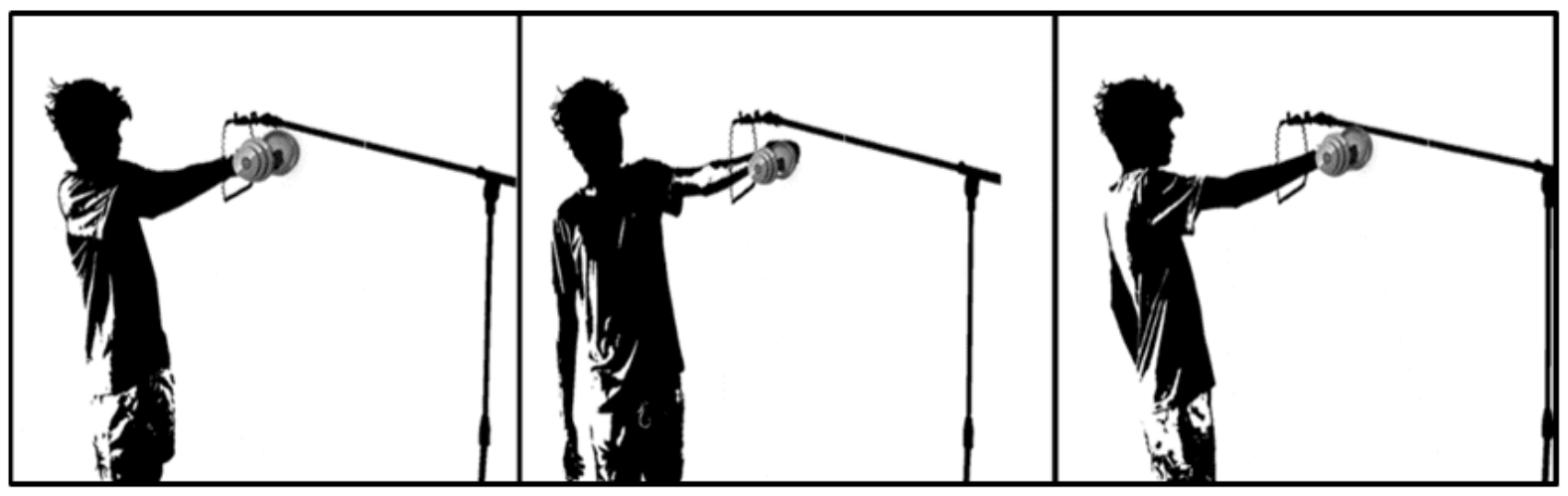

Fonte: elaboração própria, 2021.

RC: 88483

Disponível em: https://www.nucleodoconhecimento.com.br/engenharia-eletrica/mesmo-ciclo 
Apesar de parecer simples a observação, acaba sendo muito complexo o entendimento sem compreendermos as entropias associadas. No Perpetuus Motuus acontece semelhante ao experimento da figura 8 , onde as válvulas, sistema de resfriamento, controles de pressão e ajustes de velocidade fazem as compensações, fazendo com que os estágios não tenham uma ligação direta e trabalhem de forma independente, ou seja, as entropias em cada câmara não influenciam diretamente nos resultados uma das outras, fazendo com que o trabalho inicial seja menos que seu trabalho final, proporcionando assim um ganho muito superior no final do ciclo, por conta das entropias independentes apesar de estarem no mesmo ciclo.

\section{Símbolos como referências e Especificações técnicas:}

S - entropia;

S0 - entropia 0, estado da câmara de compressão com o motor desligado

Si - entropia inicial, estado da câmara de compressão com a válvula de admissão aberta e a válvula de expansão fechada

S2 - entropia 2, estado da câmara de compressão com as duas válvulas fechadas e o pistão comprimindo o ar;

S3 - entropia 3, estado da câmara de compressão com a válvula de admissão fechada e a válvula de expansão aberta;

S4 - estado da câmara de compressão, cilindro do compressor;

S5 - estado da câmara de compressão da chave pneumática;

F6 - energia elétrica gerada pelo alternador;

Fi - força inicial;

FF- força final;

RC: 88483

Disponível em: https://www.nucleodoconhecimento.com.br/engenharia-eletrica/mesmo-ciclo 
$\notin$ - não faz parte do mesmo grupo;

W- trabalho;

K- Kelvin;

$\Delta Q$ - quantidade de calor;

$\Delta S$ - Variação da entropia;

$\Delta$ Ss - soma das variações das entropias;

J - Joules;

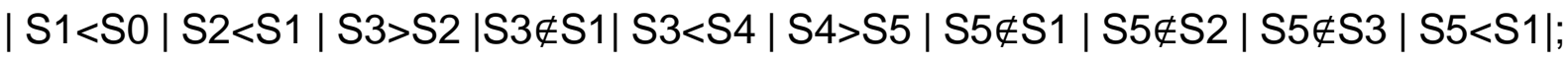


Figura 9: Especificações do compressor de ar: Figura 1.

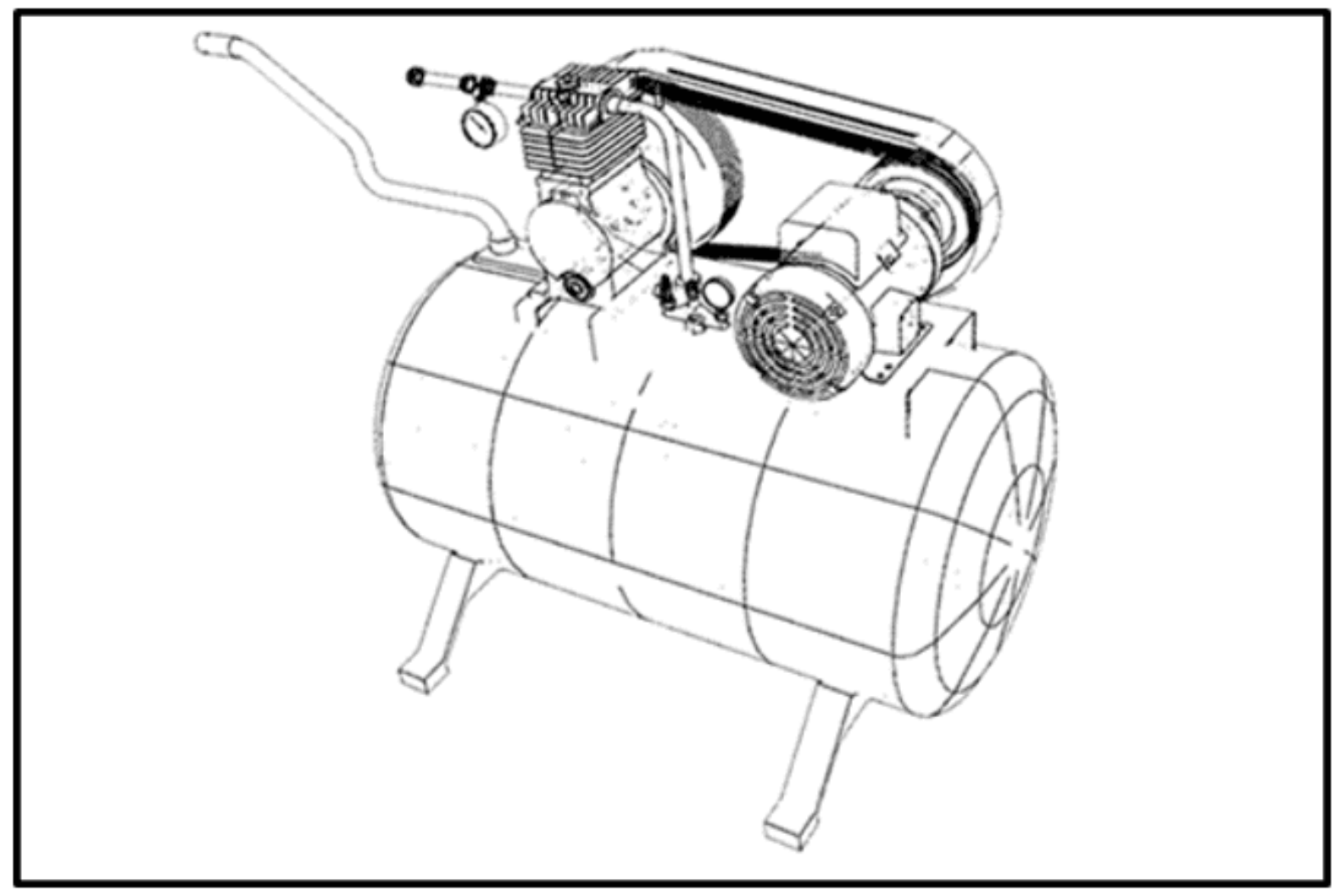

Fonte: elaboração própria, 2021.

Compressor de ar comprimido - PSI: 175, - BAR: 12: Reservatório: 250 Litros: Tempo de enchimento: 8 minutos: Número de cilindros: 2: Número de estágios: 2: dB: 76 : RPM do bloco do cabeçote: 1050: RPM do motor: 3450: Motor elétrico CV: 5 = 3.677,495 W/ 3.750 W: Número de polos: 2: Diâmetro do volante: 422: Correia.

$\mathrm{RC}: 88483$

Disponível em: https://www.nucleodoconhecimento.com.br/engenharia-eletrica/mesmo-ciclo 
Figura 10: Especificações da chave pneumática: figura 2.

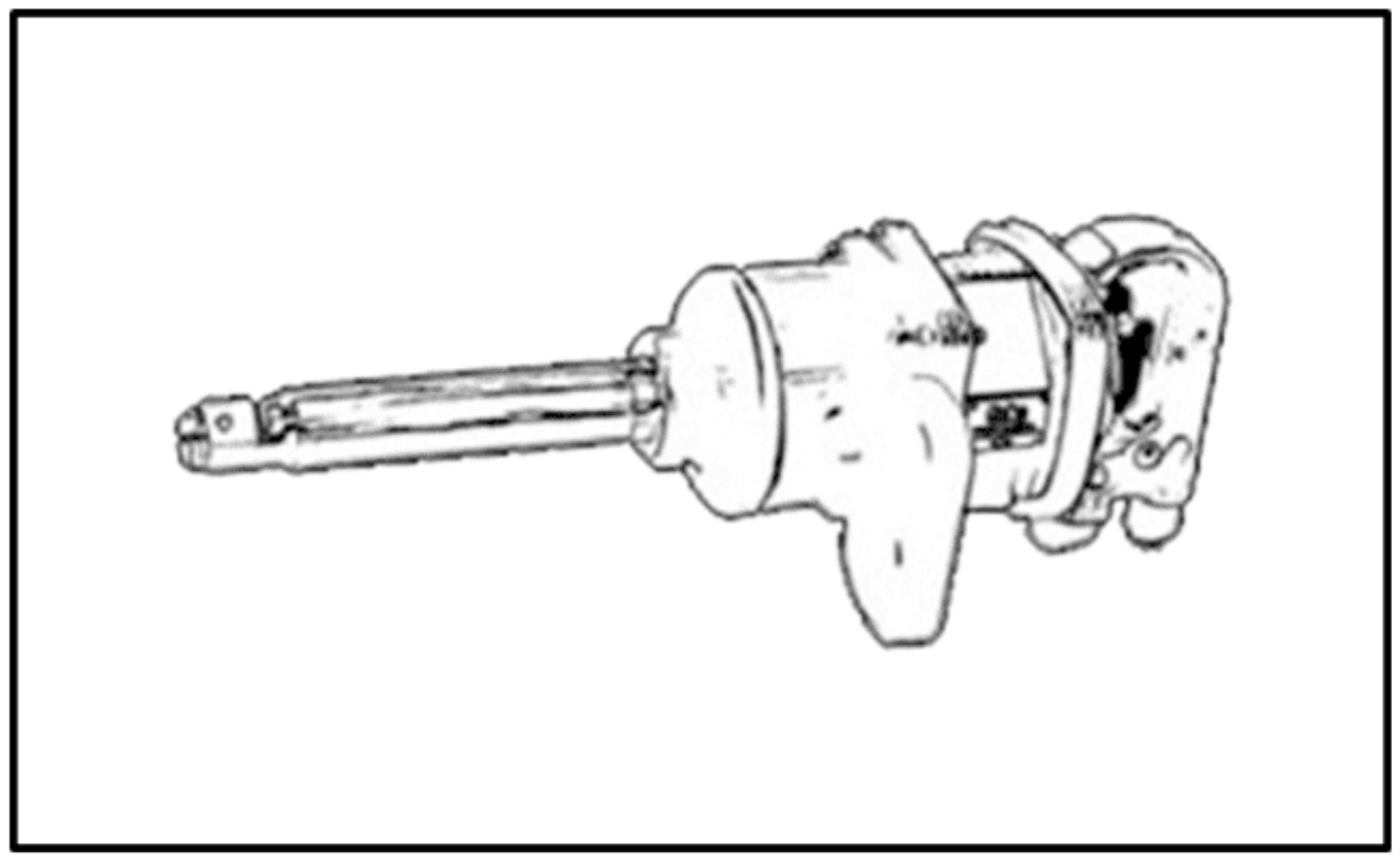

Fonte: elaboração própria, 2021.

Chave pneumática: - Parafusadeira pneumática, possui gatilho por dentro da empunhadura, ideal para trabalho em borracharias, oficinas, caminhões, ônibus, tratores etc. Gatilho para segurança do operador em ação suave, que permite um melhor controle de velocidade. Manutenção fácil, precisão nos trabalhos, uso profissional, especificações técnicas: Eixo: 1" Velocidade livre: 3.900 RPM, torque máximo: $2.400 \mathrm{~N} . \mathrm{m}, 244.8 \mathrm{Kgfm}$, capacidade do parafuso: 38mm, - entrada de ar: 1/2", - mangueira recomendada: 1/2", - pressão de ar recomendada: $8-10 \mathrm{Kg} / \mathrm{cm}^{2}, 90 \mathrm{PSI}$.

RC: 88483

Disponível em: https://www.nucleodoconhecimento.com.br/engenharia-eletrica/mesmo-ciclo 
Figura 11: Especificações do alternador de energia: figura 3.

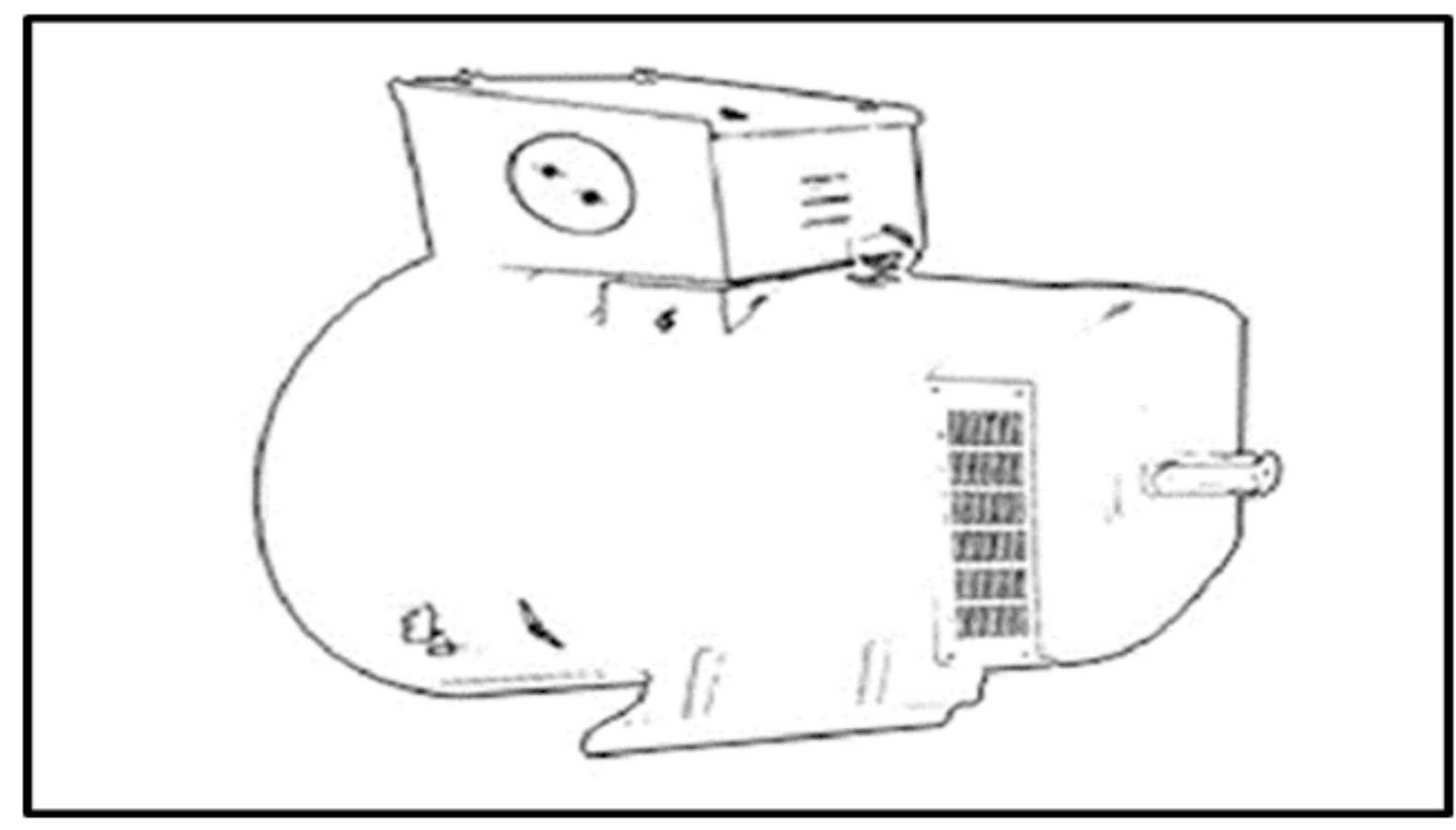

Fonte: elaboração própria, 2021.

Alternador / gerador de energia: Tipo Compound, Potência 12,9 kVA, 12900W, № de fases Trifásico, Tensão 127 V / 220 V, Frequência 60 Hz, Corrente máxima 58,4 / 33,9 A, Rotação 1800 rpm, Carcaça 180 mm, Grau de proteção IP21.

\section{CONCLUSÃO}

Conversões das energias utilizadas e geradas pelo sistema:

-90 libras $=40,82$ quilogramas

Fórmula: multiplique o valor em libras pelo fator de conversão ' 0,4536 '.

Logo, 90 libras $=90 \times 0,4536=40,8233133$ quilogramas.

$-244,8(244,8)$ quilogramas-força metro $=66690$ Watts-hora $(\mathrm{Wh})$

RC: 88483

Disponível em: https://www.nucleodoconhecimento.com.br/engenharia-eletrica/mesmo-ciclo 
Fórmula: multiplique o valor em quilogramas-força metro pelo fator de conversão '273,3'.

Logo, 244,8 quilogramas-força metro $=244,8 \times 273,3=66685,2199999$ Watts-hora (Wh).

-Trabalho inicial $=3677,495(3677,495)$ quilowatts-hora $(\mathrm{kWh})=1.3239 \times 10^{10}$ Joules (J)

Fórmula: multiplique o valor em quilowatts-hora (kWh) pelo fator de conversão '3.6005 $\times 10^{6}$. Logo, 3677,495 quilowatts-hora $(\mathrm{kWh})=3677,495 \times 3.6005 \times 10^{6}=1.3238982$ $\times 10^{10}$ ou 13238982000 Joules $(\mathrm{J})$.

-Trabalho final $=12900$ quilowatts-hora $(\mathrm{kWh})=4.644 \times 10^{10}$ Joules $(\mathrm{J})$

Fórmula: multiplique o valor em quilowatts-hora $(\mathrm{kWh})$ pelo fator de conversão '3.6 × $10^{6}$. Logo, 12900 quilowatts-hora $(\mathrm{kWh})=12900 \times 3.6 \times 10^{6}=4.644 \times 10^{10}$ ou 46440000000 Joules $(\mathrm{J})$.

\section{Cálculos da variação das entropias no sistema}


Figura 12: $\Delta S 1=$ Variação da entropia no estágio 1.

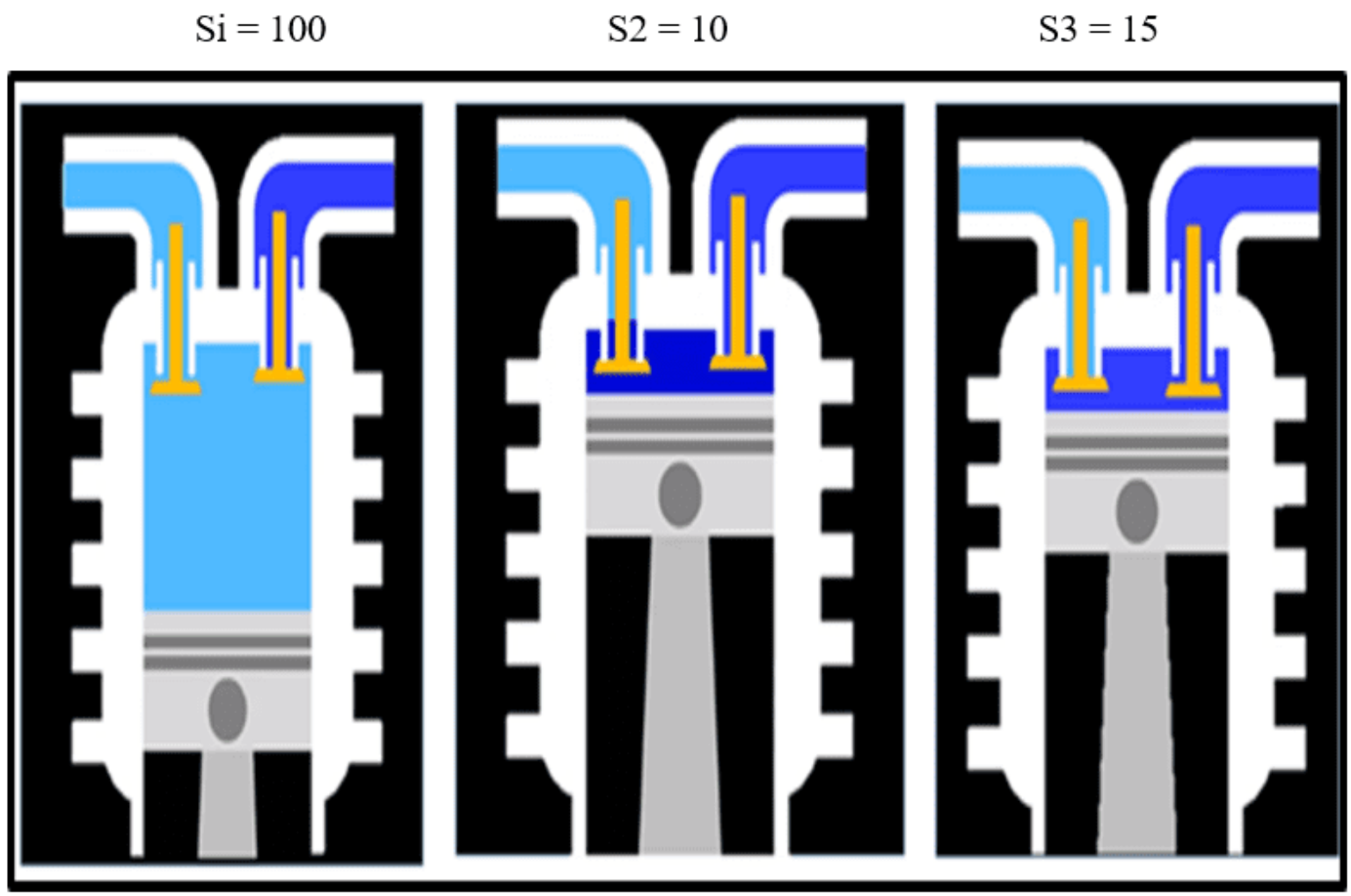


Figura 13: $\Delta S 2$ = Variação da entropia no estágio 2.

$$
\Delta \mathrm{S} 1=>\mathrm{S} 2<\mathrm{S} 3
$$

$$
\mathrm{S} 3=15
$$

$$
\mathrm{S} 4=25
$$
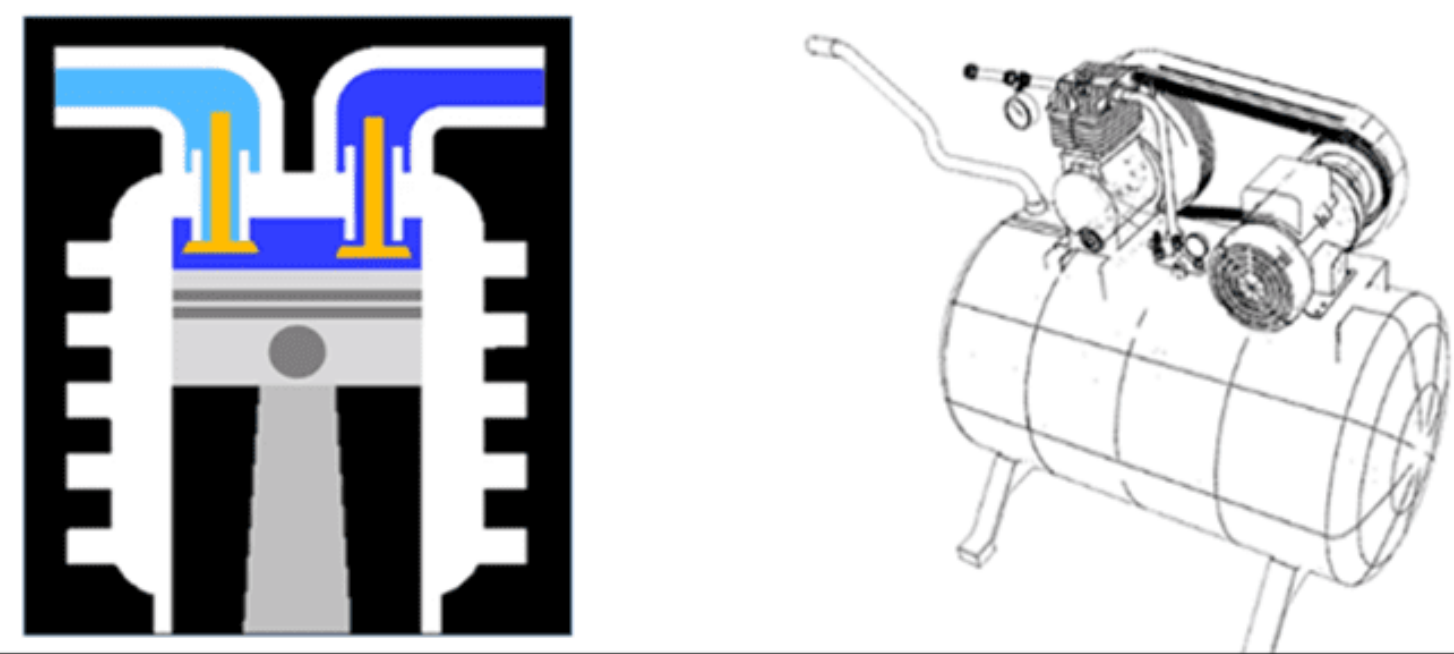

Fonte: elaboração própria, 2021.

$\mathrm{RC}: 88483$

Disponível em: https://www.nucleodoconhecimento.com.br/engenharia-eletrica/mesmo-ciclo 
Figura 14: $\Delta S 3$ = Variação da entropia no estágio 3.

$$
\Delta \mathrm{S} 2=>\mathrm{S} 3<\mathrm{S} 4
$$

$$
\mathrm{S} 4=25
$$

$$
\mathrm{S} 5=5
$$

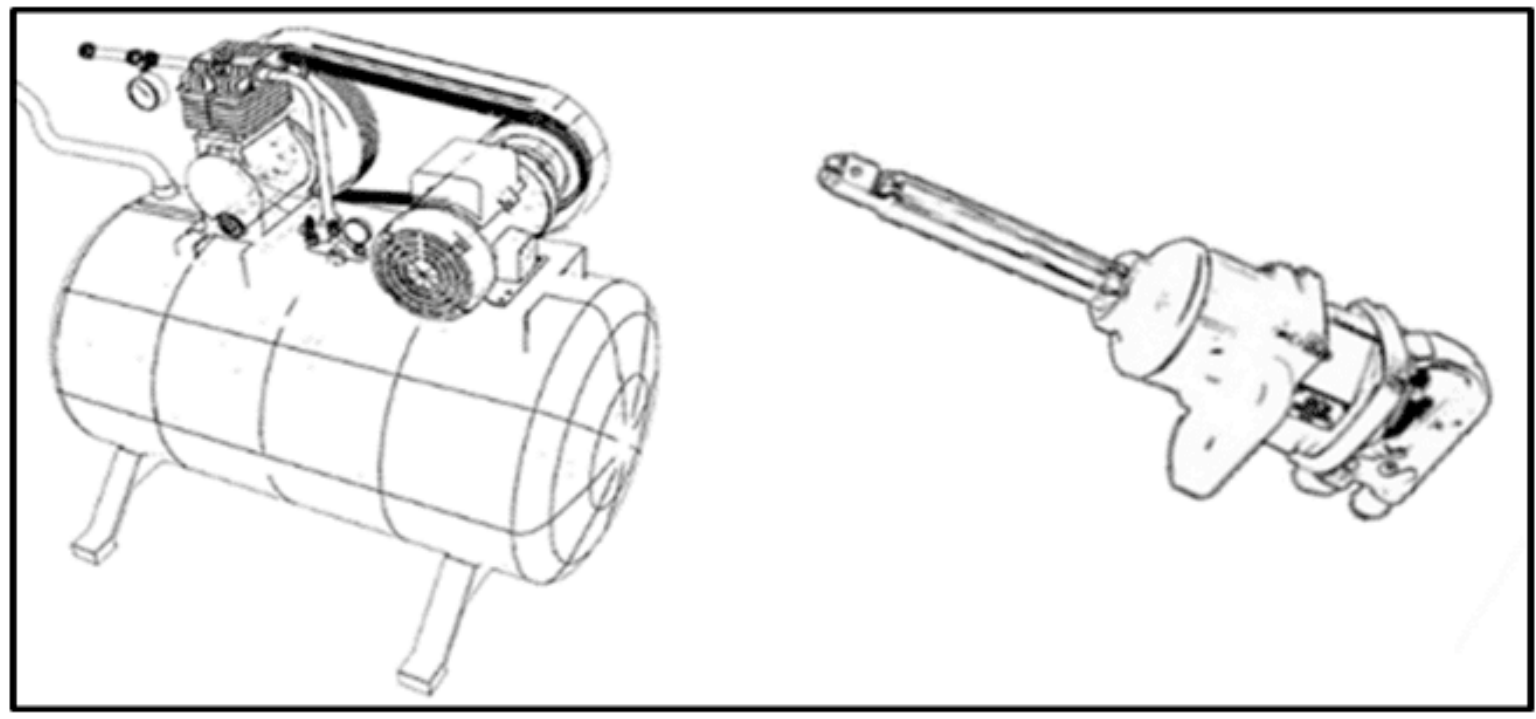

Fonte: elaboração própria, 2021.

$\Delta S 3=>S 5<S 4$

Os valores usados para representar as variações das entropias no sistema, são valores hipotéticos, pois se fossem colocados os valores reais seriam absurdamente altos, mas as diferenças que determinam quais são maiores ou menores que $(><)$ estão corretas, (JEARL WALKER, 2016).

$\mathrm{ISi}>\mathrm{S} 2, \mathrm{~S} 3, \mathrm{~S} 4, \mathrm{~S} 5|\mathrm{~S} 2<\mathrm{Si}, \mathrm{S} 3, \mathrm{~S} 4| \mathrm{S} 4>\mathrm{S} 3, \mathrm{~S} 5|\mathrm{~S} 5<\mathrm{Si}, \mathrm{S} 2, \mathrm{~S} 3, \mathrm{~S} 4| \mid \Delta \mathrm{S} 1<\Delta \mathrm{S} 2$, $\Delta \mathrm{S} 3|\Delta \mathrm{S} 3<\Delta \mathrm{S} 2| \Delta \mathrm{S} 2>\Delta \mathrm{S} 1, \Delta \mathrm{S} 3 \mid$.

$\Delta S=\mathrm{Sf}-\mathrm{Si}$

$\Delta S 1=15-10=5$

$\Delta \mathrm{S} 2=25-15=10$

RC: 88483

Disponível em: https://www.nucleodoconhecimento.com.br/engenharia-eletrica/mesmo-ciclo 
$\Delta \mathrm{S} 3=5-25=-20$

$\Delta \mathrm{Ss}=\Delta \mathrm{S} 1+\Delta \mathrm{S} 2+\Delta \mathrm{S} 3$

$\Delta \mathrm{Ss}=5+10+(-20)$

$\Delta \mathrm{Ss}=-5$

$\Delta \mathrm{S}=\mathrm{Sf}-\mathrm{Si}$

$\Delta S=-5-(100)=-105$

$\mathrm{S} f<\mathrm{Si}=>$ A entropia diminuiu.

Com base nas especificações técnicas e experimentos realizados foi observado um resultado satisfatório de ganho de trabalho e consequentemente força elétrica, pois o motor do compressor consome $3.677,495$ whats para seu funcionamento enquanto 0 sistema produz 12.900 whats; tendo uma sobra de 9.222,505 Whats. Vale ressaltar que o sistema aqui proposto poderá ser montado em diferentes tamanhos, usando diferentes equipamentos que funcione com ar comprimido, onde os mais populares são: chave pneumática, parafusadeira pneumática, pistola pneumática, britador pneumático, batedor pneumático ou mecanismos que realize qualquer tipo de trabalho para girar, vibrar, empurrar, suspender, abaixar. As potências e tamanhos variam de acordo com as necessidades de cada projeto. Se comparado com a energia solar, fotovoltaica, eólica e outras similares, o sistema proposto tem inúmeras vantagens, tais como: Espaço físico reduzido, menor custo de implantação, praticidade na implantação, não depende de condições climáticas, gera em qualquer momento independente de sol, vento ou chuvas.

De acordo com a primeira Lei da termodinâmica a energia não pode ser criada e não surge do nada; isso é de fato uma grande verdade, porém uma das vantagens do Perpetuus Motuus é que a energia acumulada em forma de pressão de ar comprimido pode ser armazenada e levada de um local para outro, possibilitando a iniciação do

$\mathrm{RC}: 88483$

Disponível em: https://www.nucleodoconhecimento.com.br/engenharia-eletrica/mesmo-ciclo 
sistema em qualquer momento dependendo apenas de um fluxo de ar para seu funcionamento.

\section{CONSIDERAÇÕES FINAIS}

Por meio deste trabalho mostramos o desenvolvimento e testes iniciais de um Perpetuus Motuus, um sistema que trabalha em um ciclo inteligente utilizando o ar comprimido para a produção de energia mecânica/elétrica, trabalhando a partir de uma força inicial, dependendo apenas de um fluxo de ar e da vida útil dos equipamentos para produzir energia indefinidamente. Foi evidenciado a Entropia independente no mesmo ciclo, fenômeno físico proporcionado pela cibernética em sua terminologia. Compreendemos como e porque a energia pode ser gerada, potencializada e transformada, tornando possível produzir mais do que seu consumo, constatando-se a assim, a entropia independente no mesmo ciclo. Deste modo, esse projeto trará diversos benefícios para a sociedade por ser uma fonte renovável de energia, grande capacidade de produção, custo baixo, capaz de produzir em um pequeno espaço físico, não vulnerável a condições climáticas e com níveis baixos de impactos ambientais. Deste modo é impossível o Perpetuus Motuus acontecer na natureza de forma espontânea sem uma pessoa que possa criar tal sistema devido a tecnologia e inteligência associada.

\section{REFERÊNCIAS}

WALKER, Jearl. Fundamentos de física, gravitação, ondas e termodinâmica, décima edição. Rio de Janeiro: LTC, 2016, pág. 643, volume 2, (ISBN 978-85-2163206-1).

- Fundamentos de física, gravitação, ondas e termodinâmica, décima edição. Rio de Janeiro: LTC, 2016, 552, volume 2, (ISBN 978-85-216-3206-1), (processos Irreversíveis e Entropia Halliday \& Resnick).

$\mathrm{RC}: 88483$

Disponível em: https://www.nucleodoconhecimento.com.br/engenharia-eletrica/mesmo-ciclo 
. Fundamentos de física, gravitação, ondas e termodinâmica, décima edição. Rio de Janeiro: LTC, 2016, 550, 551, volume 2 (ISBN 978-85-216-3206-1) (Entropia e a Segunda Lei da Termodinâmica, Halliday \& Resnick).

Fundamentos de física, gravitação, ondas e termodinâmica, décima edição. Rio de Janeiro: LTC, 2016, 252, volume 2 (ISBN 978-85-216-3206-1) (variação da entropia, Halliday \& Resnick).

Fundamentos de física, gravitação, ondas e termodinâmica, décima edição. Rio de Janeiro: LTC, 2016, 564, volume 2 (ISBN 978-85-216-3206-1), (entropia no mundo real: Máquinas Térmicas, Halliday \& Resnick).

. Fundamentos de física, gravitação, ondas e termodinâmica, décima edição. Rio de Janeiro: LTC, 2016, 597, volume 2, 20-17 (ISBN 978-85-216-3206-1), (Uma Visão Estatística da Entropia, Halliday \& Resnick).

Fundamentos de física, gravitação, ondas e termodinâmica, décima edição. Rio de Janeiro: LTC, 2016, 485,486, volume 2 (ISBN 978-85-216-3206-1), (Halliday \& Resnick, a teoria cinética dos gases, o número de avogadro).

- Fundamentos de física, gravitação, ondas e termodinâmica, décima edição. Rio de Janeiro: LTC, 2016, 182, volume 2 (ISBN 978-85-216-3206-1), (Halliday \& Resnick, teorema do trabalho e energia cinética).

YOUNG e FREEDMAN, Física II, termodinâmica e ondas, $12^{\mathrm{a}}$ edição.São Paulo: Pearson Education do Brasil, 2008, 293 - 302, (ISBN 978-85-88639-33-1), (Sears \& Zemansky, entropia).

YOUNG e FREEDMAN, Física II, termodinâmica e ondas, $12^{\mathrm{a}}$ edição. São Paulo: Pearson Education do Brasil, 2008, 284-292, cap. 20.4, (ISBN 978-85-88639-33-1), (Sears \& Zemansky, Refrigeradores).

Enviado: Abril, 201.

RC: 88483

Disponível em: https://www.nucleodoconhecimento.com.br/engenharia-eletrica/mesmo-ciclo 
Aprovado: Junho, 2021.

RC: 88483

Disponível em: https://www.nucleodoconhecimento.com.br/engenharia-eletrica/mesmo-ciclo 